\title{
LA GLOCALIZACIÓN Y SUS CONSECUENCIAS: APUNTES SOBRE LOS TEMPOREROS EN LA FRUTICULTURA LERIDANA
}

\author{
THE GLOCALIZATION AND ITS CONSEQUENCES: NOTES ON \\ SEASONAL WORKERS IN THE LERIDA FRUIT GROWING
}

\author{
Anna Mata Romeu \\ Universidad de Lleida. Lleida/España \\ annamata@geosoc.udl.cat
}

Recibido/Received: 15/07/2018

Modificado/Modified: 10/09/2018

Aceptado/Accepted: 22/09/2018

\section{RESUMEN}

Cada primavera-verano, en la campaña de la fruta en la zona sur de la provincia de Lleida, se lleva a cabo alrededor de 20.000 contrataciones relacionadas con la recogida del producto agrícola. Estas contrataciones de corta duración corresponden a trabajadores temporeros que, en su mayoría, provienen de otros puntos del estado y son de procedencia extranjera. El texto muestra los resultados de un trabajo de investigación que pretendía conocer los pormenores de organización y desarrollo de esta campaña frutícola. El trabajo de campo incluía: entrevistas a informantes claves; la realización de un cuestionario a 900 trabajadores temporeros que trabajaban en las tareas de recolección; un cuestionario a 150 empleadores de los mismos; además de análisis documental e información periodística. Se reflejan los perfiles de los diferentes agentes implicados y los discursos, las vicisitudes, aciertos e incertidumbres en torno a los que ésta se desarrolla.

\section{PALABRAS CLAVE}

Campaña agrícola; trabajo temporal; inmigración.

\section{SUMARIO}

1. Introducción. 2. Metodología. 3. Las campañas agrícolas en la huerta leridana. Cartografía de contratadores y contratados. 4. "La campaña, al rojo vivo". 5. Vicisitudes de la campaña agrícola. 6. Reflexiones finales. Bibliografía.

\footnotetext{
ABSTRACT

Every spring-summer, in the campaign of the fruit in the south zone of the province of Lleida, takes place around 20,000 hiring related to the collection of the agricultural product. These short-term contracts correspond to temporary workers, who, for the most part, come from other parts of the state and are from foreign sources. The text shows the results of a research work that sought to know the details of the organization and development of a fruit of this campaign. Field work included: interviews with key informants; the carrying out of a questionnaire to 900 seasonal workers who worked in the collection tasks; a questionnaire to 150 employers of them; as well as documentary analysis and journalistic information. It reflects the profiles of the different agents involved and the discourses, vicissitudes, successes and uncertainties around which it develops.
} 


\section{KEYWORDS}

Harvest season; Temporary Job; Immigration.

\section{CONTENTS}

1. Introduction. 2. Methodology. 3. The agricultural campaigns in the leridana orchard. Cartography of contracting and contracted parties. 4. The campaign, to the red-hot. 5. Twists and turns of the agricultural campaign. 6. Final thoughts. References.

\section{INTRODUCCIÓN}

La parte sur de la provincia de Lleida inició en los años 50-60 del pasado siglo un rápido proceso de especialización en la producción de productos hortofrutícolas. Esta especialización, tras el ingreso de España en la Comunidad Económica Europea, significó una profunda transformación en la estructura socioeconómica de la zona e incluso en las pautas socio-culturales y de vida de los pequeños pueblos que la conforman.

Este modelo productivo implicaba la necesidad de gran cantidad de mano de obra de forma estacional (primavera-verano). Una mano de obra no calificada que se fue cubriendo, desde los inicios hasta la actualidad, en un primer momento con población de la zona y pueblos colindantes; posteriormente con población de otras partes del estado español y conforme avanzaba el presente siglo, con población de procedencia extranjera (inmigrantes).

La circunstancia de ser un trabajo estacional, no calificado, muy intensivo (con largas jornadas de trabajo, que pueden incluir los siete días de la semana), que se realiza a la intemperie y mal remunerado ha ocasionado a lo largo de estos años que se acojan al mismo los demandantes de ocupación que se encuentran en los escalafones más bajos o aquellos que, directamente, no pueden acceder al mercado de trabajo regularizado.

Debido a las dificultades de articular la campaña de recogida de fruta, las diversas organizaciones y entidades sociales de la zona sur de la provincia de Lleida empezaron a organizarse y coordinarse para recibir, albergar y atender en sus diversas necesidades a toda la población que arribaba de forma descoordinada año tras año.

Este es el escenario en el que se forjan nuestras preguntas de investigación:

a) ¿Cómo se han gestado y desarrollado las campañas agrícolas anteriores, por parte de los diferentes agentes sociales? ¿Cuáles han sido sus puntos fuertes y débiles, a tenor de la opinión de los diferentes agentes implicados?

b) ¿Cuál es el perfil de las personas que, temporada 2015, cubren estos trabajos agrícolas?

c) ¿Cuál es el perfil de los contratadores agrarios? ¿Cuáles son las principales dificultades o eventualidades en las que se encuentra el empresario agrario en el momento de contratación y desarrollo de la campaña?

\section{METODOLOGÍA}

Para dar respuesta a estas preguntas se planeó una metodología que combinaba técnicas cuantitativas y cualitativas y se estructuraba en tres fases (tres periodos de tiempo). La investigación fue financiada por la Diputación de Lleida.

El trabajo de campo cualitativo consistió en entrevistas a informantes claves: representantes institucionales y de entidades sociales implicadas en la organización y seguimiento de la "campaña agrícola estival". Así se entrevistó a representantes de sindicatos 
agrarios, trabajadores municipales, técnicos del Departamento de Agricultura de la Generalidad y representantes del Gobierno Civil.

La parte cuantitativa consistió en la realización de un cuestionario a trabajadores temporeros que trabajaban en las tareas de recolección y, paralelamente, un cuestionario a empleadores de los mismos.

$\mathrm{Y}$, como hemos indicado, se fue configurando en tres fases diferentes. Una primera de entrevistas en profundidad a personas conocedoras de la campaña 2014 para analizar cómo se llevó a cabo, las situaciones que se vivieron, los puntos fuertes y débiles existentes en la organización y los factores incontrolables que se produjeron.

Una segunda fase de la investigación persiguió encuestar tanto a contratadores como a temporeros que trabajaban o estaban buscando trabajo durante los meses de la campaña agrícola del año 2015, es decir, en el trabajo de campo en los puntos agrícolas, se buscaba encuestar, a la par, a los contratadores y contratados. Los criterios de representatividad y la selección de los lugares eran cualitativos y se hicieron a partir de las indicaciones recibidas por los expertos entrevistados en la primera fase.

En los primeros, la muestra fue de 150 personas que daban trabajo a temporeros durante la temporada agrícola del verano de 2015 y se perseguía definir los perfiles de empresarios, sus preferencias en la contratación de temporeros y dificultades/utilidades con que se encontraban durante la campaña agrícola. Se procuró que estuvieran representados los diferentes tipos de contratadores agrícolas, atendiendo a la dimensión de las explotaciones, el tipo de variedades frutales y el número de trabajadores por explotación; así como una representación de la mayoría de los municipios de la zona estudiada.

En los segundos se encuestó a 900 personas, buscando la variedad de contextos y realidades; así se realizó en diferentes partes del territorio, de ambos sexos, lugares de procedencia, tipos de vivienda y situación contractual. La encuesta se llevó a cabo paralelamente al cuestionario a contratadores.

Por último, la tercera fase de la investigación partió de las dos anteriores y replicó entrevistas en profundidad de la fase uno para obtener una visión más global de la campaña agrícola 2015. Es decir, se profundizó en la valoración que de la misma hacían "a posteriori" los agentes implicados, buscando conocer cuales habían sido los aciertos o desaciertos, si habían funcionado los dispositivos previstos, etc. para poder colaborar a mejorar la campaña siguiente y las sucesivas.

Esta base empírica, de fuentes primarias, se ha complementado con artículos y noticias aparecidas en la prensa local y autonómica sobre la campaña agrícola de 2016 y 2017; también con entrevistas informales mantenidas con agentes locales municipales y contratadores agrícolas.

Así, el presente artículo muestra una parte de los resultados de este vasto trabajo de investigación y pretende reflexionar sobre los entresijos, complejidades y contradicciones de las campañas agro-frutícolas en el campo leridano del decenio actual, atendiendo a la realidad que narran los diversos actores implicados, especialmente los pequeños empresarios agrícolas y los trabajadores temporeros que participan de la misma.

\section{LAS CAMPAÑAS AGRÍCOLAS EN LA HUERTA LERIDANA. CARTOGRAFÍA DE CONTRATADORES Y CONTRATADOS}

España ha sido un país históricamente muy vinculado a la actividad agrícola, tanto es así, que esta actividad no perdió su estatus de principal sector empleador hasta la década de los 
70 del siglo pasado. Fue en ese período cuando se consiguió una fuerte recuperación económica motivada por la apertura a los mercados exteriores, el aumento de la inversión pública, la construcción de infraestructuras y la aparición de España como destino turístico internacional (Requena, 2008). Para la agricultura española fue el inicio del primer gran éxodo rural, iniciando definitivamente el declive del sector primario en pos de puestos de trabajo más atractivos en las crecientes industrias de las ciudades o en el sector servicios vinculados con el comercio urbano o las zonas turísticas. Esta situación fue consolidada finalmente por la entrada de España en la Unión Europea y su afianzamiento como economía del sector servicios (Requeijo González, 2005).

Así, el sector agrícola, principal sector ocupacional en España hasta los años 70 desciende hasta situarse por debajo del $5 \%$ del total de población activa del país. A la par asistimos al incremento sostenido del sector servicios (que ocupaba en 2015 al 65,25\% de la población activa). En opinión de López y Rodríguez (2010) este incremento pone cifras a la consolidación del modelo desarrollista en nuestro país; modelo basado en la potenciación de la construcción y el turismo como modelo socioeconómico.

Este modelo, junto con las mejoras en la formación y cualificación laboral, favorecerá la tendencia a ocupar puestos en la industria y los servicios, en detrimento del sector agrícola. Aunque, en opinión de Gordó et al. (2015), fueron también las condiciones de trabajo que ofrecía el sector agrícola: carácter cíclico, menor consideración social y sueldos más bajos, las que acarrearon que, a principios de los años noventa del pasado siglo existiese una carencia de trabajadores para atender las diversas tareas generadas en el campo, en particular las más intensivas en el uso de mano de obra (como la recolección de cosechas).

Los años de bonanza económica significaron, por una parte, la consolidación del trasvase de población activa del sector primario al secundario y terciario, por una parte; $\mathrm{y}$, asimismo, la consolidación de España (en especial las provincias de Huelva y Lleida) como productor y exportador hortofrutícola de primer orden.

Esta condición de productor y exportador conllevó, sin embargo, la instauración de una economía de escala basada en la pervivencia de ocupaciones de alta estacionalidad, baja especialización y bajos salarios. La población activa, en la medida en que podía acceder a ocupaciones de menor estacionalidad y dureza y mejores salarios, dejaba estos puestos sin cubrir o los abandonaba sin terminar su vigencia contractual (Torres et al., 2013)

Como nos recuerda Velasco Castro (2009) la alteración de una estructura social conlleva un cambio en los elementos que la componen. El agro español ha tenido profundas trasformaciones en los últimos años, como son la producción intensiva, la introducción de nuevas tecnologías o, centrando la atención en el tema de este artículo, los trabajadores que laboran en él.

Si bien es cierto que la aparición de la fruticultura ilerdense comenzó en los años sesenta con la introducción de las especies de frutales que hoy abundan, las tecnologías de cultivo consideradas modernas y las primeras cooperativas, el fenómeno no acabó de consolidarse hasta los años ochenta (Pascual Roca, 2010). En esta época es cuando hicieron su aparición la agricultura intensiva y la consiguiente introducción del sector agrícola en el mercado internacional y coincide con la entrada de España en la Unión Europea y su consiguiente acceso a consumidores de otros países (Carpintero, 2015).

En este contexto internacional, la competitividad de una región se basa en la extracción intensiva de los recursos, lo que en el caso de la Plana de Lleida supone la especialización de toda la zona en una única producción mediante la ya mencionada fruticultura intensiva.

Este fenómeno comporta, a su vez, dos nuevas realidades que acabarían determinando el mercado laboral agrícola: le necesidad de grandes cantidades de trabajadores y la corta 
duración de los puestos ofertados.

La primera de estas realidades se explica por las propias características de los cultivos frutales. No obstante es cierto que la introducción de tecnologías agrícolas reduce la necesidad de contratar mano de obra, esto es algo aplicable a producciones como los cereales. En el caso de la producción agrícola que más abunda en Lleida, las frutas requieren de una recolección manual que implican grandes números de contrataciones. Al mismo tiempo, el hecho de que los cultivos estén limitados a pocas especies implica que la ocupación, mayoritariamente, sólo se producirá en los momentos de poda, aclareo y recolección, que tienen una duración de pocos meses (Torres, Allepuz y Gordo, 2013).

Es aquí donde surge la necesidad de contratar a un tipo de trabajador muy concreto, uno que sólo trabaje durante este periodo de tiempo y después abandone el territorio para buscar un trabajo similar en otra zona. Estos trabajadores son los que hoy en día conocemos como temporeros.

Ya a inicios de la década de los noventa se empezó a detectar esta realidad. En sus trabajos en Cáritas, Tabares (1990) se refiere a los temporeros como jornaleros o jornaleras que abandonan su lugar de residencia habitual para buscar trabajo en otro sitio, ya que en ese otro lugar no hay braceros suficientes para cubrir esos puestos de trabajo temporalmente.

Tradicionalmente, el trabajo agrícola había recaído en el agricultor y su familia, quienes labraban sus campos a lo largo del año y sus ingresos provenían de las diferentes producciones que generaban y vendían en los mercados locales. Este modelo, en opinión de Bretón provenía del modelo autárquico propiciado por el franquismo y fue variando con la implantación del regadío en amplias zonas del centro-sur de la provincia de Lleida y la expansión de los mercados (Bretón y Mateu, 2000). También venía siendo tradicional la "ayuda mutua" o cooperación entre vecinos para ayudar en los momentos de mayor intensidad de trabajo, aunque, según Etxerraceta (1994:140) la modernización del sector llevó al declive de esta cooperación entre agricultores.

La llegada de la agricultura intensiva y su ya mencionada especialización y mecanización, implicaron que no fuera suficiente una familia para conseguir la cosecha; no hay que olvidar, asimismo, que, dentro del sino familiar, diversos miembros tendrán otras obligaciones laborales (y ya no estarán disponibles para la recolección). Esto conllevará una demanda de mano de obra, que se cubrirá con trabajadores temporeros.

Por tanto, según Achón (2010) a finales de los años ochenta y principios de los noventa, la producción se llevará a cabo con la colaboración de las familias del propietario más la contratación de otras familias provenientes de diferentes puntos del estado español.

En esta nueva tesitura los agricultores contarán con trabajadores poco calificados de diferentes partes del estado español. Contratarán trabajadores en paro, estudiantes (que aprovechan sus vacaciones veraniegas para ganarse algún dinero) y trabajadores llegados de otras CCAA más pobres (especialmente Extremadura y Andalucía).

A partir de los años noventa, España consolida su economía de servicios e inicia un periodo de crecimiento económico que duraría hasta la crisis del año 2008 (Catalá, 2013).

En esta etapa de la historia reciente española se produjo un cambio en la tipología de los trabajadores que realizan los trabajos agrícolas estacionales. Los hijos de los payeses se habían formado y prefirieron adentrarse, mayoritariamente, en otros sectores económicos que ofrecían mejores sueldos y estabilidad; dejaron de participar en tareas agrícolas familiares, incluso en los periodos estivales. Los jóvenes estudiantes tampoco acudían en sus periodos vacacionales en busca de un trabajo duro, mal pagado y de poca consideración social.

La mejora de las condiciones económicas también redujo el interés de las familias de jornaleros de comunidades autónomas como Andalucía o Extremadura, en desplazarse a 
Cataluña para cubrir las campañas agrícolas. Los precios y condiciones que ofrece el sector agrícola no son atractivos para gran parte de la población desocupada española. En opinión de Márquez Domínguez (2009) preferían combinar trabajos ocasionales en sus respectivas zonas antes que trasladarse por un puesto de corta duración y sueldo bajo. Así, los pequeños empresarios agrícolas de Lleida empezaron a tener verdaderos problemas para conseguir mano de obra para sus trabajos estacionales; algunos jornaleros abandonaban a media campaña ante la posibilidad de un trabajo mejor remunerado; otros cuando habían ganado dinero suficiente y muchos cuando habían conseguido completar las peonadas suficientes (sesenta jornadas trabajadas) para percibir el subsidio agrario implantado en algunas Comunidades Autónomas españolas, los llamados Planes de Empleo Rural, implantados en 1984 (Izcara, 2007)

El sector agrícola se encontró a partir de esos momentos (finales del S. XX) con serios problemas para conseguir trabajadores que ocuparán puestos de trabajo inestable $\mathrm{y}$ escasamente pagados. Afirman los empresarios agrícolas que subir los sueldos para intentar atraer a los trabajadores que han abandonado el campo no es una opción; debido a los reducidos precios de venta del producto y el escaso poder de control que tienen sobre éste, los payeses defienden que mantener los salarios bajos son la única vía para asegurar la rentabilidad de las explotaciones agrícolas (Torres, Allepuz y Gordo, 2013). Curiosamente, en estas mismas fechas también se produjo la consolidación de la inmigración internacional en España, que si bien ya había empezado años atrás, es en esta etapa cuando se consolida. De esta manera, los inmigrantes extranjeros encontraron en los puestos vacantes del campo un nicho de empleo rápido que les permitió acceder a su primer fuente de ingresos en territorio español o, en otros casos, complementar los trabajos esporádicos hechos en otros momentos del año (Díaz Diego, 2009).

La vinculación del fenómeno de inmigración internacional y el trabajo temporero fue tal que comenzaron a hacerse habituales los casos de abusos por parte del empresariado hacia el más vulnerable colectivo de trabajadores extranjeros. Ante esta situación, muchos países europeos que también tenían temporeros trabajando en sus campos, como el Reino Unido o Francia, decidieron comenzar a desarrollar programas públicos para la gestión del fenómeno. Sin embargo, el caso español fue distinto y fueron las organizaciones de empresarios agrarios los que tomaron la iniciativa. De tal forma, estas agrupaciones de empresarios comenzaron a llevar a cabo experiencias de gestión descentralizadas a nivel local (López-Sala et al., 2016; Gordó et al., 2015).

El crecimiento económico español durante los primeros años del siglo XXI provocó que las experiencias de bajas en el campo por mejores oportunidades en otros sectores se repitieran una vez más. Las primeras oleadas de trabajadores extranjeros (inmigrantes) que atendieron y cubrieron las campañas agrícolas en sus inicios, se encaminaban ahora hacia otros sectores laborales (especialmente el sector de la construcción), abandonaban los trabajos de temporeros y dejaban una vez más a las explotaciones agrarias con escasez de mano de obra. Los empresarios agrícolas tuvieron que buscar nuevas estrategias de contratación y las encontraron en las contrataciones "en origen", donde una vez más los sindicatos de empresarios llevaron la iniciativa (Achón, 2010).

El arranque de la crisis económica en España (fechado en 2008), que disparó las cifras de personas desocupadas y el cierre de numerosas empresas, llevó al gobierno español a poner fin a esta modalidad de "contratación en origen". Los agricultores leridanos tuvieron que reclutar, otra vez, entre los demandantes de empleo residentes en territorio español, a personas interesadas en cubrir las campañas agrícolas.

En esta coyuntura considera Delgado et al. (2015:35) que al mundo rural le corresponde el 
papel de Cenicienta en la nueva modernidad, una posición de debilidad que se reproduce tanto a pequeña como a gran escala internacional. La mundialización de la producción y el consumo ha conllevado que el productor sea sólo una pieza más de un gran engranaje que delimita tanto las pautas de producción como hábitos de consumo de los alimentos. En esta tesitura se reduce al agricultor a la función de simple suministrador de materia prima para los mercados internacionales y se le desposee de la autonomía que le otorgaba el control sobre la tierra y los medios de producción sobre la misma. Como señala Álvarez (2015:5): el agricultor pinta poco, ni siquiera en las tareas de las que aún no ha sido apartado; otros deciden por él lo que tiene que producir, cómo y cuándo.

Como señalamos con anterioridad, la globalización, ha reforzado la especialización territorial y acentuado la polarización entre territorios, señalando las grandes áreas metropolitanas como dedicadas a actividades que se sitúan en las últimas fases de comercialización de mercancías y servicios; y áreas rurales como territorios abastecedores de productos primarios, que se ocupan de las primeras fases de extracción y elaboración de recursos naturales. Leborgne y Lipietz (1994) definen esta disociación territorial en términos de estrategias ofensivas y defensivas; así, las estrategias ofensivas serían las desarrolladas por los países del norte de Europa, que perseguirían la negociación de altos salarios y tareas de compra-venta y gestión de productos y servicios; por el contrario, las estrategias defensivas, a las que se ha ido relegando a las regiones del sur de Europa, comportarían la realización de tareas que implican escasa innovación, trabajos temporales y bajos salarios, entre las que encontramos las tareas de producción hortofrutícola. Avallone (2013) reafirma en sus estudios la misma realidad para las áreas agrícolas de Italia y Grecia.

La producción hortofrutícola leridana, por tanto, se situaría plenamente en el tipo de regiones perdedoras que definen estos autores, en las cuales, el imperio del capital financiero modula el funcionamiento del sistema agroalimentario y erosiona el poder de los pequeños agricultores en relación con otros actores de la cadena alimentaria; a la vez que comporta una degradación reiterada y paulatina de condiciones de trabajo y salarios percibidos. Este sistema de producción de frutas y hortalizas frescas, fue, de hecho, en opinión de Carpintero (2015) uno de los primeros en globalizarse en nuestro país, conformando pronto sus patrones de producción, inversión y distribución como «cadenas globales de productos» cuya parte "extractiva" se localiza en ciertas regiones rurales convertidas en grandes «plataformas agroexportadoras » orientadas hacia los mercados del norte (Langreo, 2009).

En estas áreas de producción hortofrutícola, entre las que se encuentra las que nos ocupa, la precariedad en las condiciones contractuales y de trabajo parece un rasgo endémico; una constante que acomete a todo aquel que se acerca en búsqueda de un empleo. Por tanto, aquellos que se acercarán y aceptarán estas condiciones serán los trabajadores más vulnerables, aquellos que realmente no cuenten con otra opción y deban aceptar un trabajo irregular, discontinuo, que se realiza bajo condiciones climatológicas muy duras, de largas jornadas, pocos periodos de descanso, mala remuneración, débiles condiciones contractuales y precariedad de vivienda. Esta norma de empleo debilita los vínculos entre trabajo y ciudadanía y tiene importantes repercusiones en las condiciones de vida y trabajo de los jornaleros (Castro, 2014). Y serán mayormente personas de procedencia inmigrante las que se ofrecerán para realizarlo.

Atendiendo a la distribución de la población activa en España (con menos del 5\% del total ocupado en el sector agrícola, según datos del Instituto Nacional de Estadística de 2016); a las condiciones del mercado laboral (caracterizado por alta precarización y bajada de salarios en términos absolutos); a la depreciación de las tareas agrícolas en la gama de posibilidades laborales del mercado de trabajo español y al hecho de que, en los últimos años, haya sido 
sobre todo población extranjera la que haya realizado las campañas de recolección, los empresarios agrícolas han tenido que trazar diferentes estrategias para conseguir finalizar con éxito la campaña agrícola (que se inicia, según las zonas y los cultivos, en el mes de mayo y finaliza en el mes de septiembre-octubre). Es en esta situación donde se plantea el estudio.

\section{LA CAMPAÑA, AL ROJO VIVO}

Con estas elocuentes palabras encabezaba un periódico local la actualidad de la campaña de recogida de fruta de 2017 en Lleida. Y detalla:

La campaña de la fruta tiene aspectos muy diversos, desde el de la producción a la comercialización, pasando por el laboral y este año se multiplican los problemas. Con una cosecha plena y de calidad, los precios vuelven a ser de ruina, mientras las denuncias sobre temporeros dan una imagen de marcha atrás en la regulación de la temporada (Segre, 30 de julio de 2017, pp. 3).

El titular, muestra, como enunciamos, la punta del iceberg de una campaña frutícola con muchas contradicciones y tensiones; reflejo, tal vez, de las contradicciones y tensiones del sistema económico y laboral estatal/mundial. Debemos tener presente que: la campaña de la fruta leridana da empleo a unas 15.000 personas (con puntas de 22.000 en momentos álgidos); recoger el producto tiene un coste estimado de 85 millones de euros en salarios, cotizaciones e impuestos; de los cuales se cifran en 66 millones los que van directamente en forma de salario a los temporeros.

Ahondaremos en esta complejidad a partir de desgranar las problemáticas y discursos de los diferentes agentes implicados.

\subsection{Los temporeros}

Como venimos diciendo, tras el fin de las denominadas "contrataciones en origen", la campaña frutícola en Lleida la realizan personas, muy mayoritariamente de procedencia extranjera, residentes en diversas partes del territorio español y que se desplazan a la ciudad durante el periodo de recogida de fruta, de forma estacional.

La encuesta realizada a las personas que estaban trabajando o deseaban hacerlo en la campaña frutícola de 2015 nos ofrece trazos más precisos de sus características y circunstancias. Nos hallamos ante un perfil de varón joven $(78,3 \%$ varones y un $70 \%$ entre los 26 y los 45 años), casado (un 65\% de las personas encuestadas declaran estar casadas) y con cargas familiares. Entre las personas no casadas (divorciadas, viudas, etc.) la mayoría son mujeres, la media de edad de éstas es un poco superior a la de los varones, y declaran también tener hijos u otros familiares a su cargo.

Sólo el 5\% del total de encuestados ha nacido en España; la gran mayoría de los temporeros provienen del continente africano (destacan países como Mali, Senegal y Marruecos) y de Rumania. Aunque con gran diferencia por sexos, es decir, son las mujeres las que proceden, en su gran mayoría, de Rumanía.

De entre las personas nacidas en España el 75\% residen en la provincia de Lleida. En cambio, en las personas nacidas en otros países, su lugar de residencia es más dispar: algunos señalan Barcelona, ciudades andaluzas, de la Comunidad Valenciana o incluso señalan como residencia Marruecos o Rumanía directamente. Un 12\% declara no tener ningún domicilio fijo o lugar estable de residencia. Preguntados sobre el tiempo de residencia en España la mayoría responde haber llegado entre los años 2001 a 2010. Señalamos, asimismo, que las 
personas nacidas en el continente africano llevan mayor tiempo de residencia en España que los provenientes de Rumanía (que, de media, llegaron en el año 2007).

Aunque el 47\% del total de los encuestados declara haber entrado de forma irregular en España, en el momento de la encuesta, sólo el 10\% declara hallarse en situación irregular; éstos son mayoritariamente varones jóvenes provenientes de África subsahariana. Un amplio 95\% declara tener permiso de trabajo, haber adquirido la nacionalidad española, o ser directamente ciudadano europeo (caso de las personas provenientes de Rumanía).

Resulta interesante conocer cómo han conocido que podrían trabajar en Lleida. Así, casi un $65 \%$, declara que por información recibida de su red social y familiar. Parecería que sólo un $8 \%$ ha recibido información de alguna oficina de empleo (respuesta que dan de forma más mayoritaria las mujeres que los hombres).

Un 30\% declara llevar varios años viniendo a la campaña frutícola leridana (la mediana apunta unos cinco años), circunstancia que señalan en mayor grado las personas de origen magrebí, en segundo lugar las personas de origen sudamericano, a mucha distancia del exiguo 2,3\% que declaran los españoles. Asimismo, las personas que declaran llevar viniendo varios años disponen en su mayoría de permiso de residencia y trabajo regularizados.

Señalan casuísticas diversas en relación a cómo consiguen un trabajo, la más declarada es el uso de relaciones personales o lazos relacionales. También se enuncia la búsqueda directa, que señalan mayormente personas de procedencia africana y que puede incluir la visita a las explotaciones, los campos o los contratadores. Las empresas de intermediación (públicas y privadas) son poco utilizadas (por debajo de un 10\%) y personas en situación irregular señalan específicamente la práctica de esperar en plazas o lugares señalados el paso de posibles contratadores.

Alrededor del $20 \%$ de los temporeros (abrumadoramente personas en situación irregular y procedentes del continente africano) declara trabajar sin contrato. Las personas con contrato (el $80 \%$ ) señalan 40,58h. de duración semanal; aunque muchos declaran trabajar una media de $2 \mathrm{~h}$. más por semana. Declaran percibir una media de $6,15 €$ por hora trabajada, si bien declaran estar dispuestos a aceptar una rebaja hasta los 5,20€ por hora.

La cuestión de la vivienda, es decir, donde se acomodan durante la campaña es un tema relevante dentro del estudio. La mitad de los temporeros declara residir en un piso o casa unifamiliar y en menor frecuencia un albergue para temporeros (30\%). Es destacable que un $15 \%$ se acomoda en almacenes, casetas o asentamientos y que en todos los casos se trate de varones africanos. En los asentamientos viven personas que trabajan de manera legal y otros que no disponen de permiso de trabajo y trabajan de manera irregular. La mayoría concatenan diferentes campañas a lo largo de España: Logroño, Valencia, Jaén, Huelva, etc. Sin embargo, el hecho de que muchos de ellos no trabajen toda la campaña, sino sólo días puntuales o con interrupciones (una semana sí, tres días no...), hace que no tengan ingresos suficientes para pagar un alojamiento. Funcionan sin ningún tipo de organización formal ni liderazgo establecido. En algunos hay una persona que se encarga de hacer la comida para todos los miembros y recibe cinco euros de cada uno correspondientes a la manutención semanal. Se trata de una sola comida al día que se realiza cuando todos están presentes para compartirla.

Entre los que residen en un piso, la situación más registrada es la de régimen de alquiler compartido entre 5 o más personas; aunque el 30\% declara que estas viviendas no disponen de equipamiento básico. Parece ser una situación repetida año tras año, puesto que, entre los que llevan años cubriendo las campañas, un $75 \%$ declara repetir en este acomodo.

En general, su nivel de satisfacción con las condiciones laborales que se ofrecen es 
correcto (una media de 6 puntos, entre el 1 y el 10, siendo 1 nada satisfecho y 10 mucho); aunque la respuesta es desigual si nos referimos a varones o mujeres (ellas se muestran mucho más satisfechas que los hombres) o según su procedencia (las personas procedentes del continente africano se sitúan en un 5, sobre 10). Si la pregunta versa sobre el trato que reciben por parte del contratador, se observa la misma proporción y dispersión de respuesta; es decir, las mujeres se sitúan en torno al 7 de valoración positiva y los procedentes del continente africano entorno al 6 (entre 1 y 10 ).

Concluimos, pues, que el perfil del temporero es un varón joven, de procedencia subsahariana, con residencia legal en España (aunque no en la provincia de Lleida) y que ha participado en la campaña agrícola en años anteriores.

\subsection{Los agricultores}

La mayoría de los agricultores encuestados (64\%) forman parte de alguna organización agraria, como sindicatos y/o cooperativas de la agricultura. Las Cooperativas Locales juegan un papel importante en la comercialización de la fruta y para proveerlos de distintos inputs (abonos y herbicidas, principalmente) necesarios para el proceso productivo. También les proporcionan servicios técnicos y de control relativos al correcto uso de dichos inputs (épocas de tratamiento fitosanitario, proporciones de los productos, etc.). Los sindicatos, además de ser organizaciones que defienden sus intereses, también facilitan la gestión de determinados servicios administrativos con distintas agencias (declaraciones de renta, planes de mejora, etc.).

Prácticamente todos los agricultores encuestados (94\%) son propietarios de las explotaciones que cultivan. Además, excepto en alguna gran explotación, realizan directamente las diferentes funciones de gestión, lo cual corrobora que no disponen de una estructura administrativa, siendo ellos mismos, o a través de sus organizaciones empresariales o con la ayuda de gestorías, los que realizan el seguimiento económico y administrativo de sus explotaciones. La actividad principal de los agricultores encuestados (98\%) es la producción de fruta y ceden a las cooperativas o a la industria agroalimentaria las funciones de manipulación y distribución de lo que producen, hasta que el producto llega a la mesa de los consumidores. Este es un punto importante en el tema que nos ocupa.

El número medio de hectáreas que dedican a la producción frutícola es de 25 hectáreas, aunque hay un grupo importante con menos de 14, y una minoría con explotaciones de grandes dimensiones. Esta distribución es el reflejo del proceso que ha sufrido el sector en las últimas décadas, que ha conducido a la desaparición de pequeñas explotaciones de menos de 10 hectáreas, y a la creación de explotaciones mayoritariamente entre las 15 y 25 hectáreas, mediante la compra o el arrendamiento de las explotaciones que por jubilación o abandono del sector quedaban libres. A la vez, han surgido explotaciones de gran tamaño que ya no responden al modelo de producción familiar, fundamentado en la fuerza de trabajo de la familia del productor que en momentos de intensidad de demanda de mano de obra la contrataban temporalmente.

La mayoría de los agricultores (77\%) contrata siempre a los mismos temporeros y lo justifican porque valoran, y en este orden: la comodidad de hacerlo así (40\%), la confianza en ellos puesto que los conocen (41\%) y porque saben que trabajan bien (61\%). El resto que no contrata a los mismos temporeros, es porque éstos, en años venideros, ya no vuelven. Asimismo, afirman contratar directamente a sus trabajadores, ya que como hemos visto anteriormente, la mayoría prefiere contratar trabajadores que ya conocen. Cuando no pueden hacerlo así, porque los temporeros no vuelven al año siguiente, utilizan otras vías, y entre ellas, la dominante es mediante contactos informales, que suponemos les proporcionan otros 
productores, trabajadores temporeros o conocidos. En este punto debemos resaltar que casi son inexistentes los contratos mediante las bolsas de trabajo, tanto públicas como privadas, así como mediante los sindicatos y organizaciones agrarias. En el estudio no hemos detectado ningún caso de contratación en origen. En este punto, las valoraciones de contratados y contratadores se complementan.

Cuando los agricultores contratan temporeros valoran en orden de menor a mayor: que sean responsables, que hayan demostrado ser de confianza y especialmente que sean buenos trabajadores. No resaltan experiencias negativas, excepto en pocos casos, en que señalan como justificación la poca profesionalidad de los temporeros contratados, o los conflictos por la diversidad de los orígenes de los contratados. Todo ello es compatible con la afirmación de que la mayoría de agricultores vuelve a contratar los temporeros que previamente ya habían contratado.

Casi todos los ocupadores prefieren para todas las actividades, que los contratados sean hombres. El intervalo de edad preferido, aunque sin mucha diferencia con los otros intervalos de edad, es el de 25 a 34 años. En el imaginario social de los agricultores predomina la idea de que las labores del campo, en particular las relacionadas con la producción frutera son desarrolladas de manera más efectiva por el sexo masculino, relacionado tal vez con las condiciones de trabajo al aire libre y con la fuerza que algunas de estas tareas requieren. Por el contrario para la manipulación de la fruta y su empaquetado prefieren a las mujeres. Preguntados los agricultores sobre sus preferencia por el origen de sus trabajadores y relacionado con las diferentes actividades de la producción y manipulación de la fruta, cabe destacar que en todas ellas prefieren mayoritariamente a los trabajadores de origen subsahariano, seguidos de los del propio estado español.

Un $25 \%$ de los ocupadores manifiesta haber contratado trabajadores sin contrato como temporeros, en momentos concretos de mucha necesidad de recolección. A pesar de ello, todos se expresan en contra de contratar personas sin papeles, por los riesgos laborales que esta práctica conlleva.

Menos de la mitad de los agricultores ofrecen algún servicio a los trabajadores, siendo la vivienda el más importante entre los que ofrecen y en menor medida el transporte; aunque es costumbre arraigada que los trabajadores se desplacen a las parcelas por cuenta del empleador (dos de cada tres declaran realizar esta práctica).

El empleador se nos muestra, así, como un pequeño propietario agrario, que prefiere contratar personas que conozca de campañas anteriores, que valora especialmente la responsabilidad en el trabajo y el conocimiento de las tareas, que en algunos casos ofrece alojamiento a los temporeros (un poco por debajo del 50\%) y en los más ofrece desplazamiento hasta el lugar de trabajo.

\section{VISICITUDES DE LA CAMPAÑA AGRÍCOLA}

El sector frutícola en los últimos años ha sufrido una crisis que le lleva a una permanente reestructuración, debido al estancamiento y caída de los precios, los problemas de exportación, y los cambios en las variedades de tipo de frutales, que están produciendo cambios constantes en el sector, que inciden entre otros aspectos en el tamaño de las explotaciones y, que conducen a un constante arranque y a replantar nuevas variedades que tienen más demanda en el mercado global. Esto requiere una fuerte capitalización de las explotaciones y produce miedos sobre su continuidad y viabilidad, ya que los agricultores tienen dudas permanentes sobre cuál debe ser el tamaño ideal de sus explotaciones, para que 
estas sean rentables, y sobre cuáles deben ser las variedades que los harán más competitivos en un sector expuesto a constantes cambios y modificaciones varietales.

La caída de los precios, no de los precios de venta al pequeño consumidor, sino de los importes que recibe el agricultor por su producto, y las dificultades de exportación por la crisis de los mercados internacionales, como el inglés y el ruso han añadido tensiones en la campaña frutícola de los últimos años.

Las consecuencias de la crisis económica global y nacional se hacen notar también. Hasta el año 2011 existían líneas de financiación públicas que permitían a los municipios la posibilidad de contratar personal para atender las necesidades de los temporeros que llegaban para la campaña de la fruta y se ocupaban de asesorar a empresarios agrícolas y temporeros, gestionaban contratos, altas en la Seguridad Social, etc. También, algunos ayuntamientos creaban una bolsa de trabajo o disponían de la figura de los responsables de alojamiento, que eran los que hacían la gestión y control diario de albergues de gestión municipal. Asimismo, se contaba con tres unidades móviles del Servicio Catalán de Colocación (SOC) que iban por todo el territorio ofreciendo su servicio de asesoramiento e intermediación.

Actualmente, el apoyo a los ayuntamientos es menor y se limita a la figura del colaborador social, que realiza la gestión de los albergues (si los hay) y apoyo a los temporeros, en lo que pueda. Las tensiones, como vemos, alcanzan a toda la escala de actores implicados en el proceso.

En esta clave cabe interpretar la huelga que convocaron los temporeros de un municipio de la zona sur de la provincia de Lleida, Serós, a principios de junio de 2017 por el incumplimiento del convenio laboral del sector, en relación a los horarios y el precio por hora trabajada; y por las deficiencias en los alojamientos donde se acomodaban. Los temporeros afirmaban cobrar $5 €$ por hora trabajada, realizar jornadas de 9 y 10 horas diarias, siete días a la semana. Igualmente lamentaban verse obligados a alojarse en torres abandonadas, en granjas con animales o verse obligados a vivir en la calle o en asentamientos sin ninguna condición de habitabilidad. La huelga, aunque con timidez, fue iniciada también en algunos otros pueblos con características similares a los de Serós.

Este acto inflamó una campaña frutícola que, como venimos explicando, acarreaba malestares y tiranteces de forma larvada desde años anteriores.

Aunque las organizaciones agrarias y representantes institucionales afirmaron de forma unánime que estas irregularidades eran muy minoritarias y que, en general, la mayoría de los contratadores cumplía con los convenios del sector, desde los sindicatos de trabajadores (UGT y CCOO) las declaraciones fueron más divergentes, así:

(...) lindan con la esclavitud las condiciones de vida de los trabajadores que se han puesto en huelga en la población, con alojamientos que son sólo de cuatro paredes de ladrillos sin ventilación (miembro de CCOO en declaraciones al diario SEGRE de 2 de junio de 2017).

(...) sigue habiendo casos de sueldos de miseria, jornadas de doce horas y personal sin dónde ir a dormir (miembro de CCOO en declaraciones al diario SEGRE de 3 de junio de 2017).

Una de las piedras de toque del conflicto sería la cuestión del alojamiento. El hecho de que la gran mayoría de temporeros procedan de diferentes partes del territorio español, junto con el hecho de que, desde la crisis del 2008, desapareciesen las ayudas institucionales existentes para la contratación de albergues o la gestión de alojamientos temporales por parte de sindicatos agrarios ha ocasionado una ley del "sálvese quien pueda" que va desde la "patada 
en la puerta al alojamiento digno" (Titular del diario SEGRE de 30 de julio de 2017). Así, el Defensor del Pueblo del Parlamento Autónomo catalán decidió actuar de oficio y personarse en los asentamientos de temporeros de la zona sur de la provincia para comprobar "in situ" las condiciones de alojamiento (Visita realizada el 16 de julio de 2017). Tras su visita declaró que los asentamientos constituían una grave vulneración de los derechos humanos y que eran viviendas extremadamente precarias en materia de salubridad, higiene y seguridad (Diario $A R A$ de día 17 de julio de 2017, pág. 19). Por su parte, las organizaciones agrarias demandan una mayor implicación de las Administraciones en la gestión de los temporeros y sus alojamientos, dado que consideran que, tras el fin de los contratos "en origen" y las regulaciones del gobierno, "les han dejado solos y sin ningún tipo de soporte o ayudas" (Miembro de "Unió de pagesos" en declaraciones al diario SEGRE de 30 de julio de 2017).

Otra piedra de toque procede del lado de los contratadores, la caída de los precios de la fruta, que conlleva que los costes de producción sean superiores a lo que reciben por su venta. Denuncian que se les paga entre 15 y 25 céntimos por un kilo de fruta que ha costado entre 30 y 35 de producirla y que el consumidor la paga a más de un euro y medio en el supermercado. Además, acusan a las administraciones de pasividad ante las condiciones abusivas que impone "el oligopolio de la distribución" (Diario ARA del día 28 de julio de 2017, pág. 11). Así, se organizó una "Plataforma en defensa del sector de la fruta" que convocó marchas lentas de vehículos desde los pueblos implicados hasta la Delegación de la Unión Europea, en Barcelona. Los concentrados pedían la declaración de "estado de crisis" para el mercado de fruta y una mayor implicación de las Administraciones en la regulación del sector de producción y distribución. De hecho, los productores aseguran que la crisis de precios se arrastra desde 2014 y que no podían aguantar una nueva campaña con precios "ruinosos" porque están descapitalizados. Afirman que "el campesinado vende sus productos a un precio situado por debajo de su coste real, con un diferencial del $700 \%$ respecto del valor que paga el consumidor; pero nada cambia: los intermediarios no piensan renunciar a sus ganancias ni el Gobierno a sus impuestos ", por lo que, aseguraban," los agricultores sufrimos una explotación laboral permitida por todos" (Diario digital El Nacional de 28 de julio de 2017). Estas reivindicaciones han sido suscritas y defendidas también por los agricultores del "Bajo Cinca", comarca limítrofe, de la Comunidad Autónoma de Aragón, dado que aseguran tener los mismos problemas y reivindicaciones. En este mismo sentido, según el diario SEGRE, en su edición de 12 de agosto de 2017, las movilizaciones y reivindicaciones llegarán a los agricultores franceses, que presentan una problemática similar.

Etxerrazeta (2006:147) resulta elocuente, en este sentido: "Uno de los ámbitos donde con mayor claridad se manifiesta la división internacional del trabajo en la agricultura y la influencia de las grandes empresas transnacionales comercializadoras de productos agrarios básicos es el constituido por los mercados mundiales de productos agrarios. Por lo tanto, cualquier consideración de la evolución de la agricultura en un área o país concreto ha de tener en cuenta la situación de los mercados mundiales como uno de los elementos significativos que van a afectar su dinámica.". A tenor de la autora, por tanto, contratadores y contratados formarían parte del mismo ecosistema de producción y distribución, sobre el cual poco o nulo control tendrían.

Cabe decir, asimismo que, en el trabajo de investigación llevado a cabo en el año 2015, algunos de los agentes entrevistados ya avanzaban como indefectible la situación ahora producida en 2017, debido a la falta de previsión, la poca implicación de las Administraciones, la complejidad del fenómeno y los bajos precios de la fruta. Así reflexionaban que: 
El precio lo encontré flojo, porque, al final, si las cosas no van bien, el agricultor también recorta. Si este año has perdido dinero, el próximo deberás recortar o bien en seguros o intentar... Es un peligro. El miedo que te hace cuando no van bien los precios es que es fácil caer en la tentación, es: ¿cómo lo hago? Si en mano de obra puedo evitar unos cuantos miles de euros, imagínate el campesino que no tiene suficiente bolsa o no puede pedir que le da miedo, si ya está hasta aqui y si tiene que pedir más crédito y no podrá pagar.... Esto hace que se tema que la contratación pueda bajar y favorece la contratación ilegal. Este aspecto creo que es el más flojo, que nos puede afectar en la campaña siguiente (Representante sindical).

La propuesta que yo tengo es que se potencien las buenas prácticas y la contratación de proximidad. Porque si una persona debe moverse por todas partes sin casa y sin nada, esto lo que hace es crear bolsas de personas en situación de exclusión social (Representante Entidad Social).

La sensación es de tapar agujeros que dejan al descubierto otros sistemas. Creo que los servicios que se prestan son dignos pero insuficientes. Queda pendiente el alojamiento de las personas que malviven en asentamientos o en casas ocupadas, vehículos... Creo que la garantía del alojamiento debería articularse de forma que redujera el impacto en la calle y mejorara las condiciones de vida, de forma global (Técnica municipal).

Es necesaria una apuesta por un modelo global que atienda el fenómeno de la llegada de temporeros desde una perspectiva integral y multisectorial. Hay que invertir esfuerzos en la lucha contra la explotación y la dignificación. Una marca de calidad de la fruta de Lleida que incorpore también las condiciones laborales en que se ha producido (Técnica municipal).

\section{REFLEXIONES FINALES}

Lo que nos muestra la investigación realizada es la indefensión: indefensión de los temporeros ante sus contratadores e indefensión de los agricultores frente a las condiciones del mercado internacional. Ante ellos unos representantes políticos, y unas entidades sociales parcheando o bien en una situación de indefinición. Todos parecen sobrepasados por un contexto de contrageografías (Sassen, 2003) o de glocalización (Robertson, 2003).

La investigación focaliza una de los problemas principales de las campañas frutícolas y un encadenamiento de factores que, juntos resultan explosivos: fin de la política de "contratación en origen"; una gran mayoría de los temporeros que se desplaza a la zona desde otras partes del estado español; tensiones por la bajada de precios de los productos y por las condiciones laborales de los temporeros; merma de presupuestos y ayudas públicas para el alojamiento de esta población itinerante, todo ello convierte la situación en insostenible.

Se desprende de ello una indefensión de los trabajadores temporeros; una inadecuación e insuficiencia de los servicios existentes para la acogida, que no responden a las necesidades presentes de los temporeros, por las condiciones en que se desarrolla la campaña y una trama de pequeños pueblos dispersos, sin condiciones para su acogida.

Igualmente, se vislumbra la escasa implicación de las Administraciones y la inexistencia 
de soluciones efectivas tanto a las demandas de los agricultores como para garantizar el buen desarrollo de las campañas agrícolas, en general.

Así, debería ser ineludible un replanteamiento de cómo se abordan y planifican las campañas agrícolas, debido a la complejidad de las situaciones actuales y la sensación generalizada de improvisación, sin abordaje de las problemáticas de fondo.

Aunque quizás este replanteamiento sea difícil realizarlo desde el marco local en que nos situamos. Señala Delgado (2017:14) que el capitalismo "en fase de descomposición" en el que nos encontramos persigue cambios en la geografía del régimen alimentario a escala mundial y que los gigantes de la agroindustria, deseosos de mayores beneficios se han lanzado a una carrera desenfrenada de especulación tanto con las tierras cultivables como con los productos y precios de aquello que se produce. La horticultura leridana debe, pues, lidiar en este tablero de ajedrez para encontrar un nuevo equilibrio entre contratadores y contratados. Este trance nos remite, por tanto, a posibilidades nuevas, que suponen ensamblajes posibles en las relaciones entre agricultores e inmigrantes, con posibilidades de alianzas inéditas, y también en las relaciones con las instituciones públicas, que en la forma vigente no han sido capaces de arbitrar y cumplir con su labor reguladora del sector (Avallone, 2013).

Cabe, en fin, plantearse qué tipo de agricultura quiere mantener la sociedad. Ello implica tomar decisiones acerca de si se opta por el proteccionismo y la autosuficiencia alimentaria, con el arraigo de la población en el medio rural; o se trabaja para la producción mundial (que conlleva la producción masiva, basada en la concentración parcelaria, que escatima en salarios y desprecia la seguridad en el trabajo) (Etxerraceta, 2006:233). En definitiva, si se opta por un modelo de producción intensiva o por uno de alta calidad -que cuide y valore el valor añadido-.

\section{BIBLIOGRAFÍA}

Achón, O. (2010) Contratación en origen e institución total. Estudio sobre el sistema de alojamiento de trabajadores agrícolas extranjeros en el Segriá (tesis doctoral). Barcelona: Universitat de Barcelona, en https://www.tdx.cat/bitstream/handle/10803/730/OAR_TESIS.pdf?sequence=1 [consulta 14/1/2018].

Álvarez, S. (2015) "Desafíos para un mundo rural vivo: cultivar la tierra, proteger al campesinado". Papeles de relaciones ecosociales y cambio global, 131: 5-9

Avallone, G. (2013) "El campo neoliberal y su crisis. Agricultura, sociedad local y migraciones en la Europa del Sur". ENCRUCIJADAS. Revista Crítica de Ciencias Sociales, 6: 39-55.

Bretón, V. y Mateu, J. J. (2000) "Propietarios, aparceros y expedientes judiciales. La lucha por la tierra en Lleida durante el primer franquismo". Revista española de estudios agrosociales y pesqueros, 186: $129-158$.

Carpintero, O. (2015) El metabolismo económico regional español. Madrid: Fuhem Ecosocial.

Castro de, C. (2014) "La desdemocratización de las relaciones laborales en los enclaves globales de producción agrícola". En A. Pedreño (Coord.) De cadenas, migrantes y jornaleros. Los territorios rurales en las cadenas globales agroalimentarias. Madrid: Talasa, pp. 59-77.

Català, S. (2013) "La crisis económica española vista desde la otra orilla". Encuentros multidisciplinares, 15(43): 72-80.

Delgado, M. (2017) "Reestructuración del sistema agroalimentario globalizado en el capitalismo terminal". Papeles de relaciones ecosociales y cambio global, 139: 13-25.

Delgado, M.; Reigada, A.; Soler, M. y Pérez Neira, D. (2015) "Medio rural y globalización. Plataformas agroexportadoras de frutas y hortalizas: los campos de Almería". Papeles de relaciones ecosociales y cambio global, 131: 35-48. 
Díaz, J. (2009) "Los campos que otros trabajan. Las campañas agrícolas españolas con mayor porcentaje de extranjeros". En M. Gordo y J. García (Coord.). Explorando los contratos en origen en los campos españoles. Huelva: Universidad de Huelva, pp. 25-67.

Etxerraceta, M. (1994) "Trabajo y agricultura: los cambios del sistema de trabajo en una agricultura en transformación". Agricultura y sociedad, 72: 121-166.

Etxerraceta, M. (2006) La agricultura española en la era de la globalización. Madrid: Ministerio de Agricultura, Pesca y Alimentación.

Gordo, M.; Allepuz, R.; Márquez, J. y Torres, T. (2015) “La gestión colectiva de los contratos en origen de temporeros colombianos en la provincia de Lleida". Boletín de la Asociación de Geógrafos Españoles, 68: 233-252.

Izcara, S. (2007) "Subsidio agrario y sociedad rural en Andalucía". Papers, 86: 203-225

Langreo, A. (2009) "Nuevas estrategias de la distribución de frutas y hortalizas", Distribución y Consumo, 106: 24-35.

Leborgne, D. y Lipietz, A. (1994) "Flexibilidad ofensiva, flexibilidad defensiva. Dos estrategias sociales en la producción de los nuevos espacios económicos", En G. Benko y A. Lipietz (Eds.) Las Regiones que Ganan. València, Edicions Alfons el Magnànim, pp. 342-361.

López, I. y Rodríguez, E. (2010) Fin de siglo, financiarización, territorio y sociedad de propietarios en la onda larga del capitalismo hispano (1959-2010). Madrid: Traficantes de sueños.

López-Sala, A.; Molinero, Y.; Jolivet-Guetta, M.; Eremenko, T.; Beauchemin, C.; Samuk, S. y Consterdine; E. (2016) "Seasonal immigrant workers and programs in UK, France, Spain and Italy". Working Paper Series. Temporary versus Permanent Migration, 2016/01, TEMPER EU Project.

Márquez, J. A. (2009) "Jornaleros forasteros y extranjeros en la frontera agraria". En M. Gordo y J. Felicidades, (Coord.) Explorando los contratos en origen en los campos españoles. Huelva: Universidad de Huelva, pp. 185-210.

Pascual, M. (2010) "La fructicultura a Lleida”. En D. Babot, et al. (Coord.) L'Agricultura a les Terres de Lleida en el segle XXI. Lleida: Publicacions de La Mañana, pp. 35-52.

Requeijo, J. (2005) “La era del Quantum: 1960-1974”. Revista de economía, 826: 25-37.

Requena, M. (2008) "Bases demográficas de la sociedad española”. En J.J. González y M. Requena (ed.) Tres décadas de cambio social en España. Madrid: Alianza, pp.141-164.

Robertson, R. (2003) Glocalización: tiempo-espacio y homogeneidad-heterogeneidad. Cansancio del Leviatán: problemas politicos de la mundialización. Madrid: Trotta.

Sassen, S. (2003) Contrageografias de la globalización. Género y ciudadanía en los circuitos transfronterizos. Madrid: Traficantes de sueños.

Tabares, E. (1990) Jornaleros y Temporeros. Madrid: Cáritas Española.

Torres, T.; Allepuz, R. y Gordo, M. (2013) "La contratación de mano de obra temporal en la agricultura hortofrutícola española". Revista de Estudios sobre Despoblación y Desarrollo Rural, 16: 7-37.

Velasco, A. J. (2009) "Epistemología de representación del cambio social”. Episteme, 29 (2): 114-144.

\section{Breve currículo:}

\section{Anna Mata Romeu}

Doctora en Sociología por la Universidad Pública de Navarra (2007). Profesora Titular del Departamento de Geografía y Sociología desde 2002 en la Universidad de Lleida. Líneas de investigación: a) Los procesos de exclusión-integración social, b) Las migraciones internacionales y los procesos de acomodación, c) Investigación en el marco de proyectos de cooperación internacional, d) Nuevas herramientas para la intervención social. 